\title{
Analisa Anomali Bawah Permukaan Laut Menggunakan Data Side Scan Sonar, Sub- bottom Profiler dan 2D High Resolution Seismic
}

\author{
Ahmad Farhan Farabi dan Eko Minarto \\ Departemen Fisika, Fakultas Ilmu Alam, Institut Teknologi Sepuluh Nopember (ITS) \\ e-mail:e.minarto@gmail.com
}

\begin{abstract}
Abstrak-Konstruksi lepas pantai dalam beberapa waktu kebelakang sering terjadi bencana karna adanya kegagalan dalam menganalisa bencana geologi (geohazard). Suatu konstruksi lepas pantai jika didirikan di atas anomali yang berbahaya maka resiko terjadinya kecelakaan semakin besar. Untuk mengetahui keberadaan dari anomali tersebut maka dilakukan survei Side Scan Sonar, Sub-bottom Profiller dan 2D High Resolution Seismic dengan studi kasus di perairan Madura denngan grid 2x4 Km dengan 50 lintasan. Data yang diperoleh akan diolah menggunakan software CodaOctopus dan Seisvision. Hasil yang didapat berupa peta fitur dasar laut, profil geologi dangkal dan profil geologi menengah. Dari hasil pengolahan data maka didapat bahwa koordinat GTX-2 berada pada zona aman terhadap anomali level 1-3 dan koordinat Alternative GTX-2 berada pada zona bahaya karna tepat berada di atas anomali level 3 . Berdasarkan peta fitur dasar laut telah ditemukan beberapa objek di daerah survei yaitu pockmark, kabel, pipa dan scars trawl.
\end{abstract}

Kata Kunci-Side Scan Sonar, Sub-bottom Profiler, High Resolution Seismic, Anomali, Konstruksi lepas pantai.

\section{PENDAHULUAN}

A NOMALI dasar laut sering kali sudah dikarakteristikan diberbagai lautan di dunia. Fenomena ini merupakan bagian dari panorama alam seperti gunung dan lembah. Identifikasi anomali dasar laut sangat dibutuhkan untuk kegiatan konstruksi lepas pantai seperti peletakan platform, kabel bawah laut dan pipa bawah laut. Anomali yang terdapat di dasar laut nantinya akan dianalis a agar tidak terjadi bencana lepas pantai seperti deepwaterhorizon di teluk Meksiko akibat adanya anomali yang tidak terkontrol oleh operator yang mengakibatkan hancurnya oil rig dan mencemarkan lingkungan sekitarnya. Metode akustik atau seismik saat ini masih menjadi metode terbaik untuk memetakan anomali dasar laut karna prinsipnya adalah menangkap waktu penjalaran gelombang yang ditimbulkan dari sumber internal ataupun eksternal. Teknologi akustik yang berperan dalam survey anomali dasar laut diantaranya Multibeam Echosounder, Side Scan Sonar, Sub-bottom Profiler dan High Resolution Seismic [1].

Bencana geologi atau bis disebut geohazard menjadi titik acuan penting dalam eksplorasi minyak dan gas bumi karna dapat berakibat merusak secara kontinu yang mengakibatkan adanya kerusakan terhadap fitur dasar laut maupun jauh dibawah yang dapat merugikan konstruksi diatasnya [2]. Beberapa anomali dasar laut sudah diklasifikasikan berdasarkan sebab objek tersebut terbentuk yang biasanya karna ulah manusia dan alam itu sendiri (Tabel 1).
Tabel 1.

List Objek Dasar Laut [3]

\begin{tabular}{llll}
\hline \hline \multicolumn{2}{c}{ Man-Made Object } & \multicolumn{2}{c}{ NaturalObject } \\
\hline$\bullet$ & Kabel Listrik dasar laut & $\bullet$ & Relief dasar laut \\
$\bullet$ & Pipa Minyak & $\bullet$ & Lereng dari palung \\
$\bullet$ & Sumur Minyak yang & $\bullet$ & Lubang gas \\
& telah habis & $\bullet$ & Gundukan gas hidrat \\
$\bullet$ & Jejak kaki pemasangan & $\bullet$ & Karang \\
& jack up & $\bullet$ & Parit dasar laut \\
$\bullet \quad$ Bangkai Kapal & $\bullet$ & Pockmark \\
$\bullet$ & Infrastruktur non migas & $\bullet$ & Gumpalan \\
\hline \hline
\end{tabular}

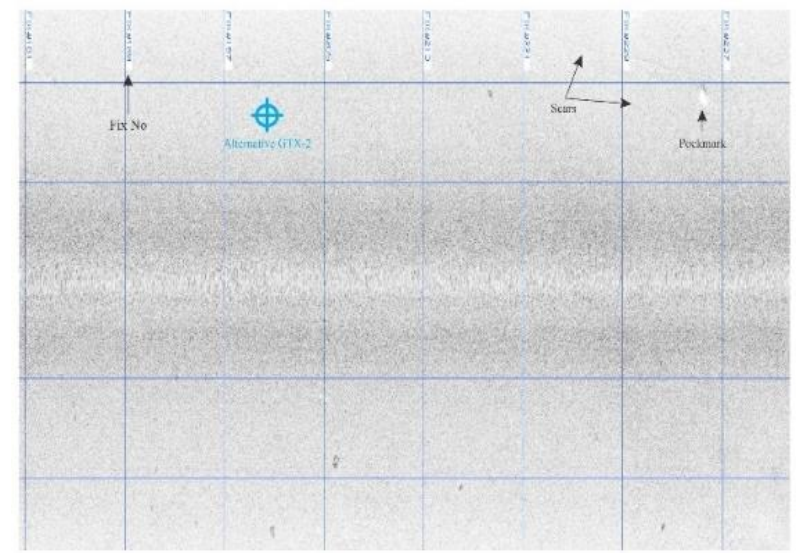

Gambar 1. Intensitas akust ik pada line 44 daerah Alternative GT X-2.

Anomali yang jauh berada dibawah dasar laut juga harus dianalis a untukmengetahui titik pengeboran tersebut aman atau tidak dengan menganalisa menggunakan data seismik yang jangkauan penetrasinya lebih dalam. Anomali tersebut bisa jadi berupa bright spot ataupun patahan kecil yang dapat mengakibatkan penurunan atau kenaikan tekanan saat proses pengeboran.

Instrumen yang umum digunakan untuk survei hidrografi adalah side scan sonar (SSS) yang mana menggunakan prinsip gelombang akustik yang dipancarkan oleh transducer dengan frekuensi berkisar antara $50 \mathrm{Khz}-1 \mathrm{Mhz}$ dimana alat itu merubah sinyal listrik menjadi gelombang mekanik yang akan menjalar dan kemudian kembali lagi ke receiver sehingga mempunyai nilai waktu tempuh gelombang [4]. Intensitas akustik yang kembali (Gambar 1) menunjukan adanya anomali berupa pockmark dan goresan akibat dari jangkar kapal. Image yang tergambar pada data tersebut nantinya akan digabungkan menjadi mozaik dan diinterpretasi sesuai intensitas gelombang akustik yang kembali ke receiver. 


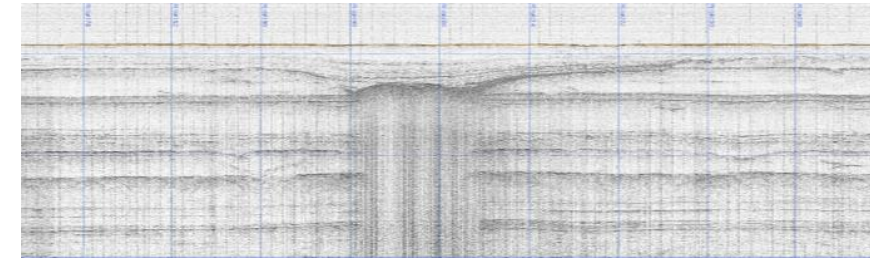

Gambar 2. Penampang Sub-Bottom Profiler.

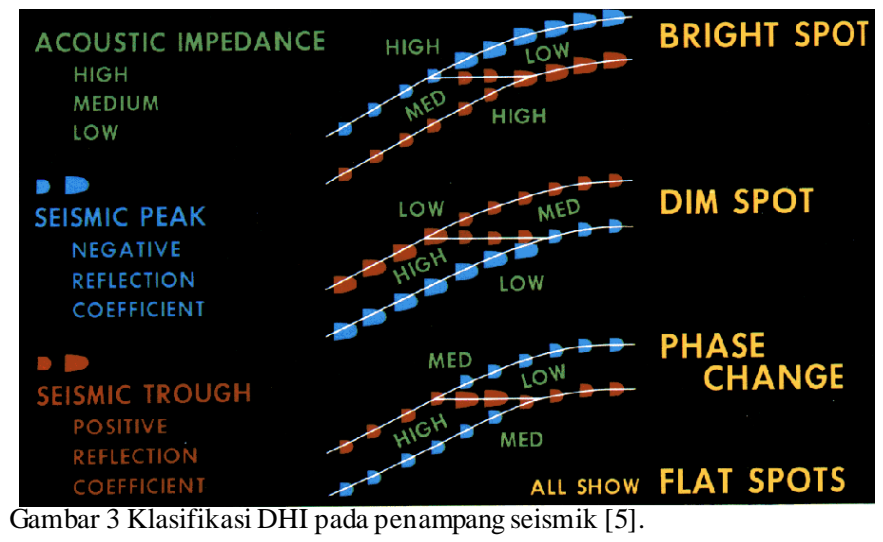

Sub-bottom Profiler (SBP) prinsipnya hampir sama dengan SSS dengan memancarkan gelombang akustik melalui transducer dan akan diterima kembali melalui receiver. Namun, pada instrumen SBP dikarenakan mempunyai frekuensi yang relatif kecil sekitar $1-300 \mathrm{Khz}$ sehingga instrument ini dapat melakukan penetrasi hingga ke dalam geologi dangkal dan dapat penetrasiantara $10-500 \mathrm{~m}$ dibawah dasarlaut.

Tipe dari SBP ada beberapa macam yang diklasifikasikan pada frekuensi dan pemasangan alatnya (Tabel 2). Sama halnya dengan SSS yang mana bila menggunakan frekuensi yang tinggi maka akan dapat penetrasi yang dalam dangkal dengan catatan resolusiakan bertambah dan begitu sebaliknya. Adapun tipe SBP dengan resolusi tinggi yaitu Chirper dan Pinger dan tipe SBP dengan frekuensi rendah yaitu boomer, sparker, air guns. Dalam sistem frekuensi rendah biasanya sumber energi terpisah dengan receiver atau hydrophone.

Dalam pembacaan data SBP juga terkadang dapat mengetahui dengan jelas dimana letak channel atau sungai purba yang terjadi karena adanya sedimentasi baru yang berada diatas sedimen yang lama (Gambar 2). Umumnya geoscientist menentukan dahulu letak reflektor pertama dari sedimen tersebut agar mengetahui kedalaman dari channel dan anomali dari data SBP.

Metode 2D High Res Seismic merupakan metode yang cocok untuk mengidentifikasi geologi dalam dikarenakan instrument ini dapat mencapai penetrasi hingga $3 \mathrm{KM}$ dibawah permukaan laut. Pada metode seismik pada umumnya menggunakan sumber gelombang yang memiliki kekuatan besar [7]. Saat gelombang yang dipancarkan kembali ke permukaan akan di tangkap oleh streamer yang merekam waktu penjalaran gelombang dari saat ditembakan hingga kembali ke permukaan karna adanya beda indeks bias disetiap lapisan [8]. Data yang digunakan telah dilakukan tahap prosesing sehingga data seismic berupa penampang post stack time migration (PSTM) yang mana reflektor sebenarnya telah diluruskan dan sudah
Tabel 2.

Tipe Sistem Sub-Bottom Profiler [6]

\begin{tabular}{lll}
\hline \hline System & Frequency & Depth of Penetration \\
\hline Sparker & $50 \mathrm{~Hz}-4 \mathrm{kHz}$ & $500 \mathrm{~m}$ \\
Chirper & $1-10 \mathrm{kHz}$ & $<100 \mathrm{~m}$ \\
Boomer & $300 \mathrm{~Hz}-3 \mathrm{kHz}$ & $<200 \mathrm{~m}$ \\
Pinger & $2-12 \mathrm{kHz}$ & $10-50 \mathrm{~m}$ \\
\hline \hline
\end{tabular}

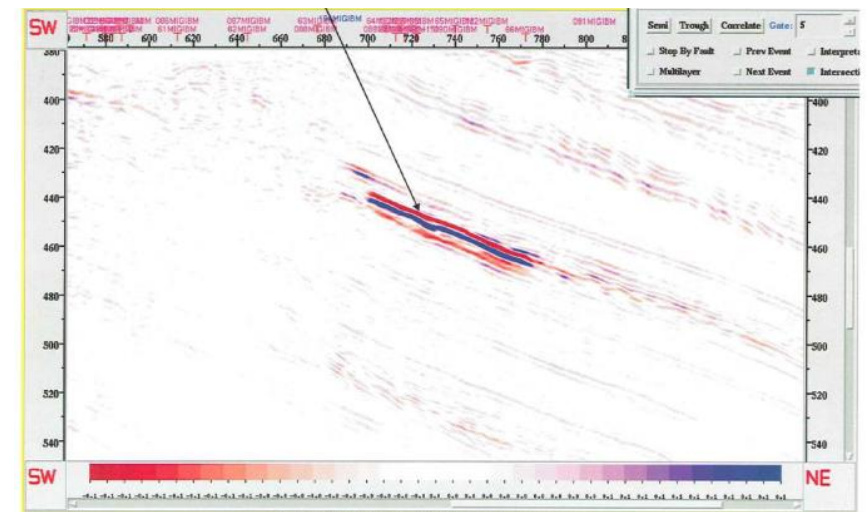

Gambar 4 brightspot pada penampang seismik [5].

dikonversikan terhadap kedalaman. Migrasi juga dapat dilihat sebagai dekonvolusi spasial yang meningkatkan resolusi lateral atau horizonal yang mengakibatkan estimasi kedalaman dalam seismic kurang akurat [9].

Dalam interpretasi data seismik harus diperhatikan factor direct hydrocarbon indicator (DHI) yang mana dapat berpengaruh pada Analisa anomali. Interpretasi anomali tersebut tergantung dari tujuan Analisa karna pada dasarnya mayoritas dari anomali ini berhubungan dengan reservoir gas daripada minyak karena efek sifat akustik gas pada ruang pori secara signifikan lebih besardari pada minyak [10]. Jenis jenis DHI yang terlihat pada penampang seismik sebagai anomali meliputi brightspot, dimspot dan phase reversal (Gambar 3) Namun, bright spot tidak semua disebabkan oleh gas terkadang batuan karbonat, batuan beku dan lapisan tipis bisa saja menghasilkan koefisien refleksi yang tinggi [11] sehingga dapat membuat amplitude seismik yang tinggi dibandingkan dengan penampang lainnya (Gambar 4).

Lapisan pada batubara juga dapat menghasilkan amplitude yang tinggi dengan koefisien refleksi yang negative seperti pada ciri ciri brightspot [12]. Berkurangnya amplitudo karena adanya gas di dalam batu pasir atau reservoir disebut sebagai dim spot. Dim spot pada kasus kontak antara batu lempung dengan gas di dalam batu pasir terkompaksi atau batu lempung dengan gas di dalam batuan karbonat biasanya akan mempunyai koefisien refleksi positif [13]. Gas yang berada pada reservoir relatif mempunyai nilai impedansi akustik yang besardibandingkan dengan sedimen di atasnya.

\section{METODOLOGI}

\section{A. Lokasi Penelitian}

Pengambilan data penelitian dilakukan oleh pihak PT. Java Offshore yang berlokasi di daerah perairan Madura, Jawa Timur (Gambar 5) dengan 3 metode yaitu Side Scan Sonar, Sub-bottom Profiler dan 2D High Resolution Seismic. 


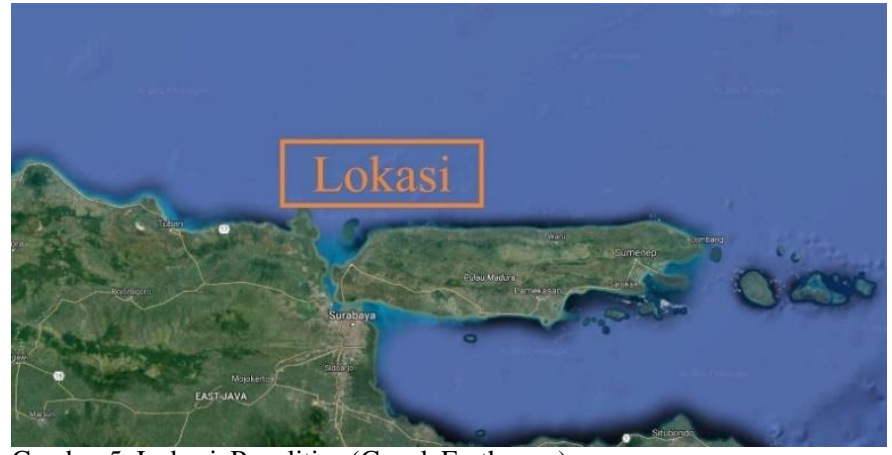

Gambar 5. Lokasi Penelitian (GoogleEarth.com).

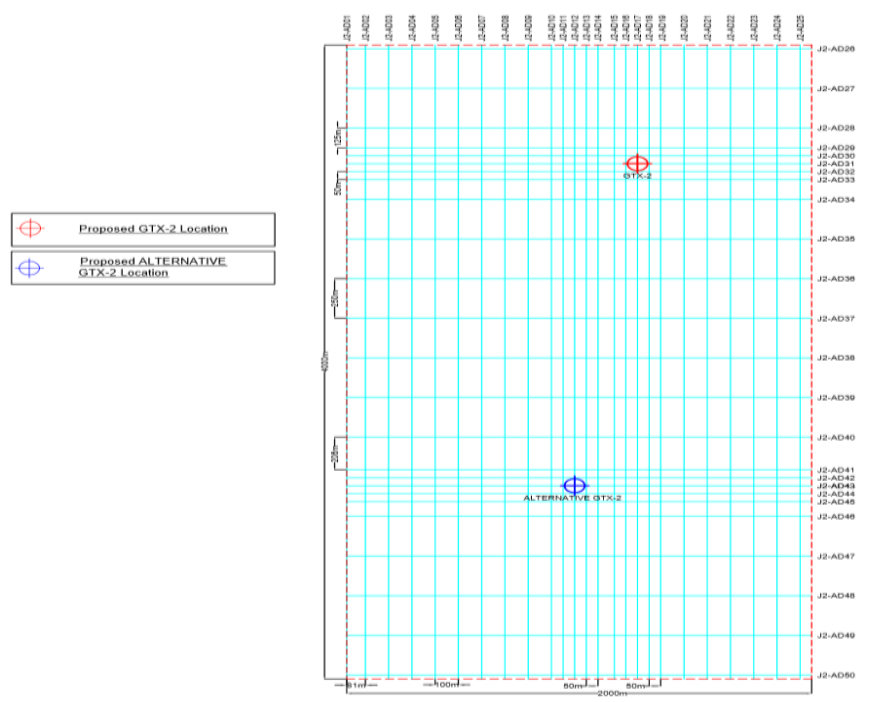

Gambar 6. Survey grid lokasi penelitian.

Terdapat dua pengajuan lokasi sumur yaitu pada GTX-2 dan Alternative GTX-2. Survei dilakukan pada grid panjang $2 \mathrm{Km}$ dan lebar $4 \mathrm{Km}$ dengan spasi antar line $50 \mathrm{~m}$ (Gambar 6). Crossline pada lokasi GTX-2 adalah line 31 dan 17, sedangkan crossline pada alternative GTX-2 adalah line 43 dan 12.

\section{B. Pengolahan Data}

Tahapan pengolahan data pada penelitian ini memiliki diagram alir (Gambar 7).

\section{ANALISA DAN DISKUSI}

Pada bab Analisa dan diskusi menghasilkan 3 bahas an pokok berdasarkan daerah anomali yang ditinjau yaitu Seabed Features, Shallow Profile dan Intermediate Profile

\section{A. Seabed Features}

Seabed features adalah suatu peta permukaan dasar laut yang berupa anomali alam ataupun buatan manusia itu sendiri. Peta ini merupakan suatu digitasi dari 2 data dimana hasil dari batimetri multibeam echosounder dan mozaik side scan sonar (Gambar 8). Data image multibeam echosounding (Gambar 9) didapatkan dari hasil survei yang dilakukan PT. Java Offshore sebagai berikut. Interpretasi dari hasil side scan sonar diketahui bahwa adanya debris, pockmark dan scars bekas dari timbunan kabel atau pipa. Peta Seabed feature sebenarnya berfungsi untuk memberikan informasi tentang objek yang berada paling dekat dengan target yang mana target disini adalah pengajuan

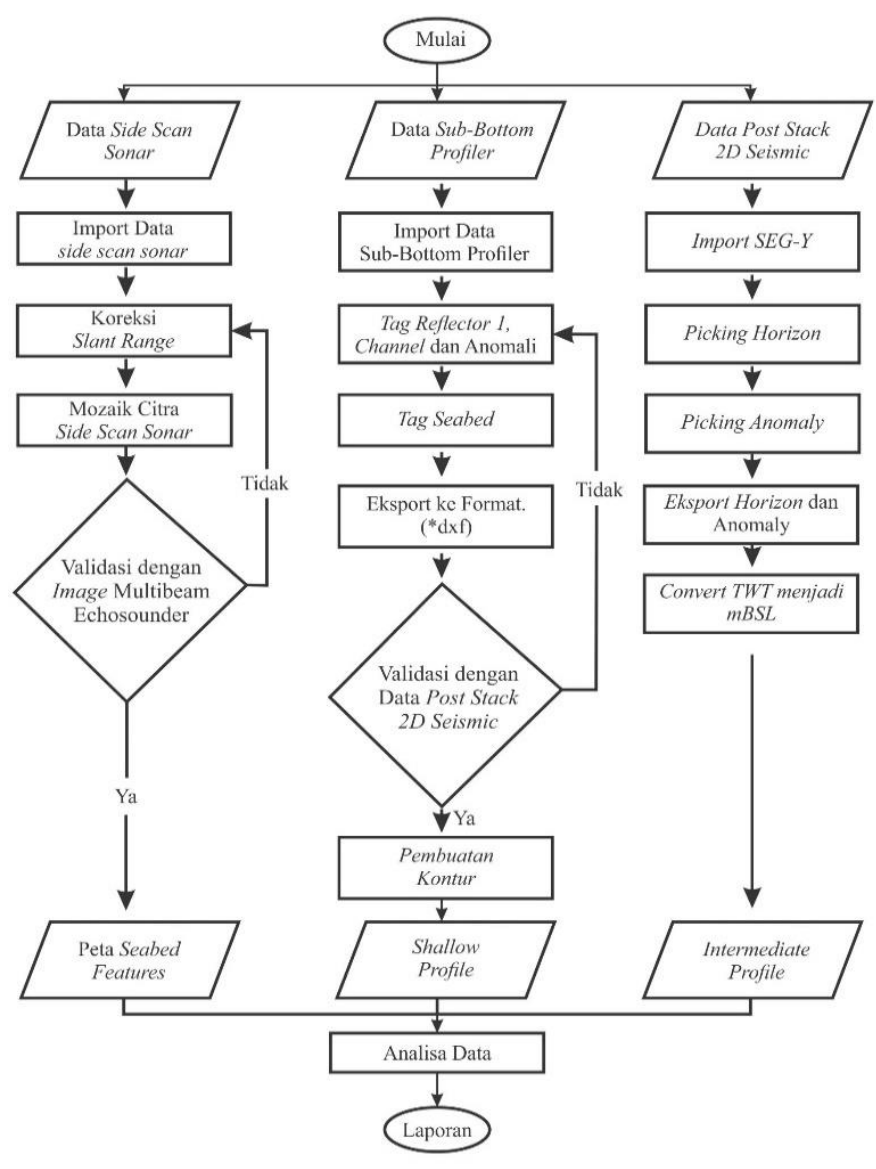

Gambar 7. Diagram Alir pengolahan data.

lapangan baru yaitu GTX-2 dan Alternative GTX-2. Untuk informasi tersebut dinyatakan dalam jarak dan kedalaman yang mana di klasifikasikan pada (Tabel 3) ini.

Pockamark ini bisa terjadi karna adanya arus air laut melalui kompaksi sedimen alam sehingga terjadi fluktuasi kedalaman dasar laut pada daerah survei. Kabel dan pipa bawah laut juga dapat mengganggu konstruksi lepas pantai karna dalam peletakan pondasitidak boleh terganggu oleh objek apapun.

\section{B. Shallow Profile}

Pada penelitian ini diidentifikasi adanya 3 level anomali yang dipisahkan berdasarkan kedalaman. Level 1 berada pada anomali dangkal dan level 2 dan 3 berada pada anomali menengah yang akan dibahas kemudian. Anomali level 1 dapat ditemukan dengan mudah oleh data sub-bottom profiler (Gambar 10) dan divalidasi dengan data 2D High Resolution Seismik (Gambar 11). Pada level 1 anomali diprediksi adanya fasa terbalik dan acoustic masking yang berasosiasi dengan shallow channel system 1. Anomali ini bisa jadi mengandung sedimen yang berisi hidrokarbon yang mayoritas berupa gas. Pada kasus ini hidrokarbon berupa gas sangat penting diidentifikasi selama pengeboran minyak karena bisa berdampak pada blow out atau kick saat pengeboran yang mana menimbulkan tekanan yang begitu tinggi sehingga sedimen dan lumpur di bawah tanah meluap hingga ke permukaan (Gambar 9). 
Tabel 3.

Klasifikasi Fitur Dasar Laut terhadap jarak dari target

\begin{tabular}{ccc}
\hline \hline Klasifikasi Fitur & \multicolumn{2}{c}{ Jarak Terdekat dari Lokasi } \\
\cline { 2 - 3 } Dasar Laut & GT X-2 & Alternative GT X-2 \\
\hline Pockmark & $16 \mathrm{~m}$ & $54 \mathrm{~m}$ \\
Kabel & $101 \mathrm{~m}$ & $476 \mathrm{~m}$ \\
Pipa & $1100 \mathrm{~m}$ & $1000 \mathrm{~m}$ \\
Scars Trawl & $457 \mathrm{~m}$ & $187 \mathrm{~m}$ \\
\hline \hline
\end{tabular}

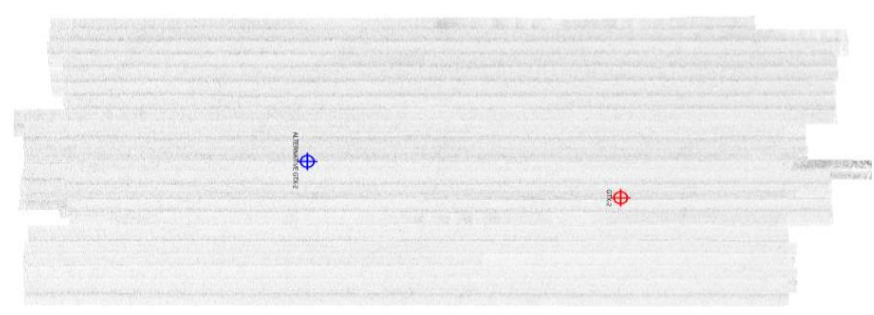

Gambar 8. Hasil Mozaik citra side scan sonar.

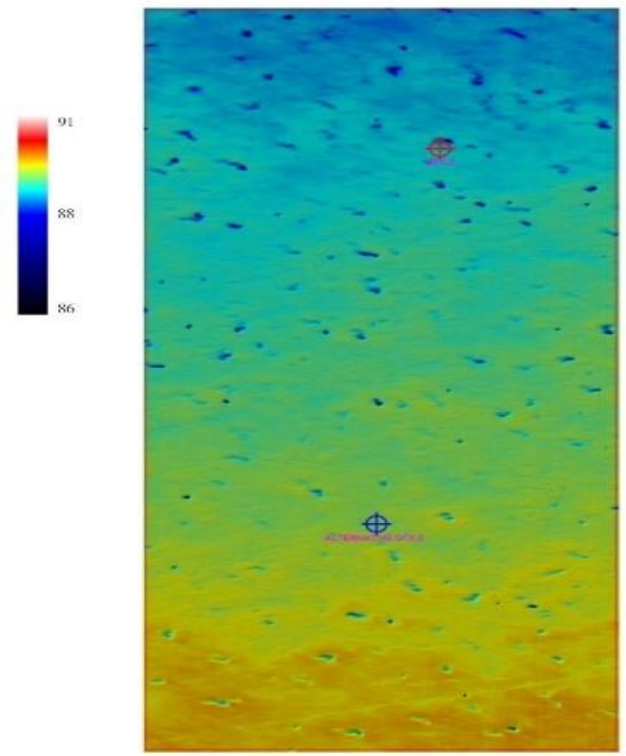

Gambar 9. Image Multibeam Echosounder.

Pada area survei anomali level 1 ini tersebar dibeberapa titik menjadi 4 bagian yang mana mempunyai lebar lateral antara 50 - $300 \mathrm{~m}$ dan memiliki kedalaman antara 15 - 19 m dibawah permukaan laut. Pada penelitian ini harus diketahuiberapa jarak target terhadap anomali (Tabel 4) agar dapat merekomendasikan lokasi yang kecil kemungkinannya terhadap bencana. Jarak terdekat lokasi GTX-2 terhadap anomali berada pada jarak $300 \mathrm{~m}$ dan lokasi alternative GTX-2 berada pada jarak $600 \mathrm{~m}$.

\section{C.Intermediate Profile}

Anomali level 2 berada pada waktu antara 167 - $171 \mathrm{~ms}$ dan dikonversikan kedalam kedalaman menjadi 130 - $133 \mathrm{~m}$ dibawah laut. Anomali level 2 ini tersebar didaerah utara dan tenggara daerah survei dan membentuk peta lateral yang cukup kecil. Berdasarkan dari interpretasi bahwa ditemukan adanya amplitude yang tinggi dengan fasa terbalik dimana negative menjadi positif begitu juga sebaliknya (Gambar 12). Anomali ini masih kemungkinan kecil adanya gas yang terdapat didalam
Tabel 4.

Jarak Anomali level 1 terhadap lokasi target

\begin{tabular}{|c|c|c|c|c|}
\hline \multirow{2}{*}{ Level } & \multirow{2}{*}{$\begin{array}{l}\text { Depth (m } \\
\text { BSB ) }\end{array}$} & \multirow{2}{*}{$\begin{array}{c}\text { Probability } \\
\text { of Being } \\
\text { Gas }\end{array}$} & \multicolumn{2}{|c|}{ Jarak Terdekat dari Lokasi } \\
\hline & & & GT X-2 & $\begin{array}{c}\text { Alternative } \\
\text { GT X-2 }\end{array}$ \\
\hline 1 & $15-19 \mathrm{~m}$ & High & $300 \mathrm{~m}$ & $620 \mathrm{~m}$ \\
\hline
\end{tabular}
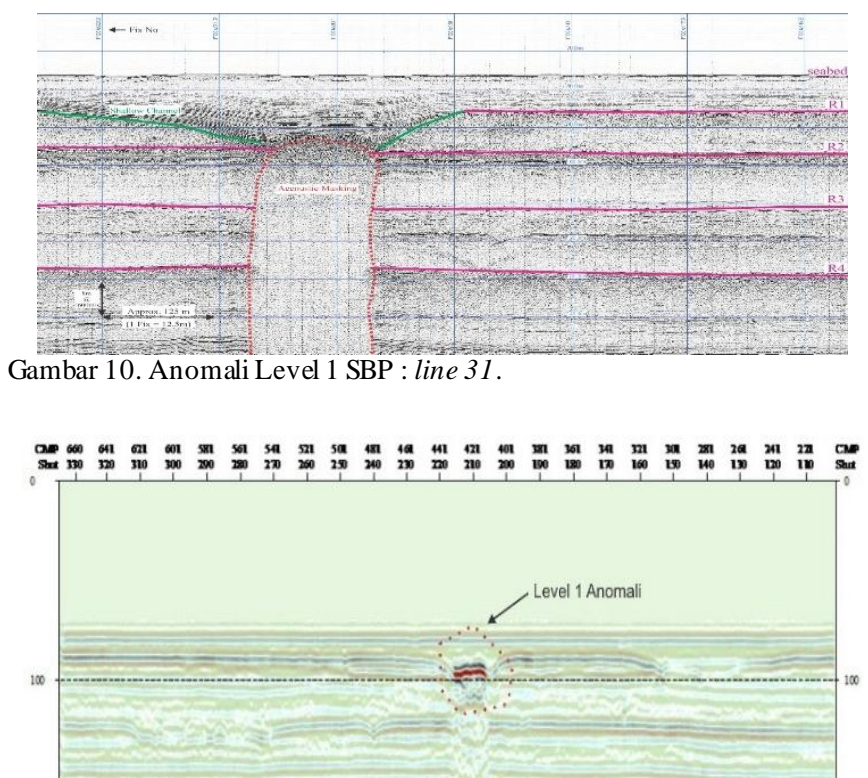

Gambar 11. Anomali Level 12D HRS: line 31.

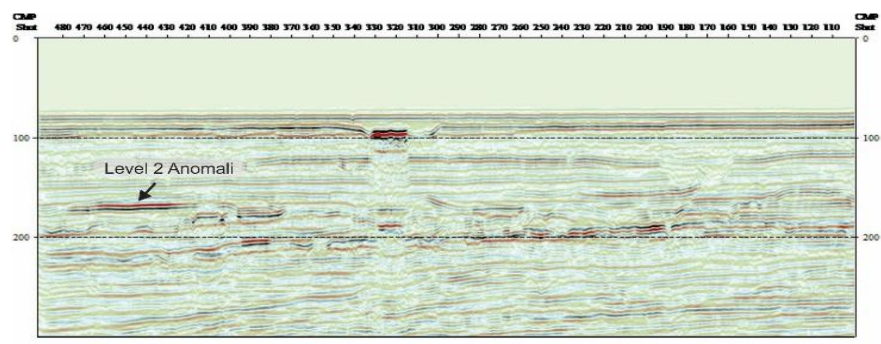

Gambar 12. Anomali Level 2 2D HRS: line 5.

sedimen karena fasa terbalik sangat sering dilihat di dalam data seismik 2D. Jarak terdekat anomali level 2 ke lokasi GTX-2 berada pada jarak $200 \mathrm{~m}$ dan jarak terdekat ke lokasi Alternative GTX-2 berada pada jarak $860 \mathrm{~m}$ (Tabel 5).

Anomali level 3 ini berada pada waktu antara $176-182 \mathrm{~ms}$ dan dikonversikan kedalam kedalaman menjadi 137 - $142 \mathrm{~m}$ dibawah laut. Anomali level 3 ini tersebar didaerah utara sebelah kiri dan tengah daerah survei dan membentuk peta lateral yang cukup kecil. Berdasarkan dari interpretasi bahwa ditemukan adanya amplitude yang tinggi dengan fasa terbalik dimana negative menjadi positif begitu juga sebaliknya (Gambar 13). Anomali ini masih kemungkinan kecil adanya gas yang terdapat di dalam sedimen karena fasa terbalik sangat sering dilihat di dalam data seismik 2D. Jarak terdekat anomali level 2 ke lokasi GTX-2 berada pada jarak $775 \mathrm{~m}$ dan jarak terdekat ke lokasi Alternative GTX-2 berada titik-nya dan berada pada kedalaman 175 TWT atau setara dengan $136 \mathrm{~m}$ (Tabel 5). 


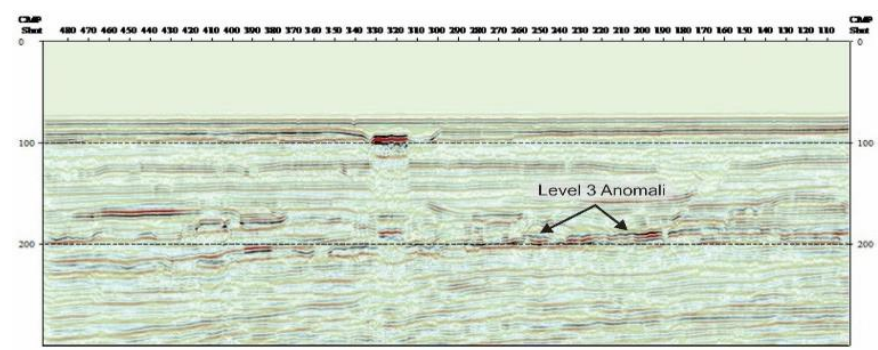

Gambar 13. Anomali Level 3 2D HRS: line 5.

\section{KESIMPULAN}

Dari 3 metode yang diproses untuk analis a anomali tersebut didapat bahwa kontur kedalaman dari reflektor 1 berada pada interval 6 - 11m di bawah permukaan laut dan letak anomali level 1-3 berada pada batas aman pada koordinat GTX-2 dan untuk koordinat Alternative GTX-2 berada pada level waspada karna berada di atas anomaly level 3 175ms TWT. Fitur dasar laut yang ditemukan pada area survei pun beragam seperti Pockmark, Kabel, Pipa dan Scars Trawl.

\section{DAFTAR PUSTAKA}

[1] Aina, "Penggunaan Metode Post Stack Time Migration dan Metoda Pre Stack Depth Migration Pada Data Seismik Lapangan Mentari," Yogyakarta, 1999.

[2] R. Holmes, "The Issue Surrounding A Shallow Gas Database In A Relation To Offshore Hazard," Edinburgh, 1997.

[3] OGP, Guidelines for the Conduct of Offshore Drilling Hazard Site Survey. Wales, 2013.

[4] H. J. Lekkerkerk, R. V. Velden, T. Haycock, P. Jansen, R. D. Vries,
Tabel 5.

Jarak Anomali Level2 dan 3 terhadap lokasi target

\begin{tabular}{|c|c|c|c|c|}
\hline \multirow{2}{*}{ Level } & \multirow{2}{*}{$\begin{array}{l}\text { Depth (m } \\
\text { BSB ) }\end{array}$} & \multirow{2}{*}{$\begin{array}{l}\text { Probability } \\
\text { of Being } \\
\text { Gas }\end{array}$} & \multicolumn{2}{|c|}{ Jarak Terdekat dari Lokasi } \\
\hline & & & GTX-2 & Alt ernative GT X-2 \\
\hline 2 & $130-133 \mathrm{~m}$ & Low & $200 \mathrm{~m}$ & $860 \mathrm{~m}$ \\
\hline 3 & $136-142 \mathrm{~m}$ & Low & $775 \mathrm{~m}$ & Tepat di Lokasi $136 \mathrm{~m}$ \\
\hline
\end{tabular}

and P. Waalwijk, Handbook of Offhsore Surveying Volume One: Preparation \& Positioning. London: Clarkson Research Service Limited, 2006.

[5] PT. Java Offshore, "Geohazard Analysis Survey Offshore West Madura, Indonesia," Jakarta, 2017.

[6] P. J. W. Siwabessy, J. D. Penrose, R. J. Kloser, and D. R. Fox, "Seabed habitat classification," in Proc. International Conference on High Resolution Surveys in Shallow Waters DSTO, 1999.

[7] A. Jamady, "Kuantifikasi Frekuensi dan Resolusi Menggunakan Seismik Refleksi di Perairan Maluku Utara,”Bogor, 2011.

[8] G. . Hutabarat, "Integrasi Inversi Seismik dengan Atribut Amplitudo Seismik Untuk Memetakan Distribusi Reservoar Pada Lapangan Blackfoot,"Makara Sains, vol. 7, 2009.

[9] A. Berkhout and D. . Wulfften, "Migration in the Presence of Noise," Geophys. Prospect., vol. 28, no. 3, pp. 372-383, 1980.

[10] A. R. Brown, "Interpretation of Three-Dimensional Seismic Data," 2010.

[11] M. Yunanda, “Analisa Atribut Seismik Untuk karakterisasi reservoir pada lapangan x Laut Utara, Netherland,” Depok, 2010.

[12] M. E. Badley, "Practical seismic interpretation," Boston, 1985.

[13] M. Hasan, "Relokasi Gempa Low Frequency pada Gunung Papandayan menggunakan Optimasi Very Fast Simulated Annealing," J. Fis. dan Apl., vol. 12, no. 2, 2016. 